PENELITIAN

\title{
Pengaruh Premedikasi Klonidin terhadap Interval Q-Tc dan Skor Rate Pressure Product pada Laringoskopi Intubasi
}

\section{Effect of Clonidine Premedication on Q-Tc Interval and Score Rate Pressure Product at Laryngoscopy Intubation}

\author{
Fajrian Noor*, Soni Hidayat**, Witjaksono**, Uripno Budiono ** \\ *Bagian Anestesiologi dan Terapi Intensif RSUD H. Boejasin, Tanah Laut, Kalimantan Selatan \\ **Bagian Anestesiologi dan Terapi Intensif FK Undip/ RSUP dr. Kariadi, Semarang
}

\begin{abstract}
Background: Endotracheal intubation laryngoscopy is an act done in general anesthesia. Laryngoscopy and intubation actions than can cause trauma, can also cause cardiovascular changes in the form of increased blood pressure, increased heart rate, increased scores rate pressure product (RPP) which increased cardiac oxygen demand and Q-Tc interval prolongation by sympathetic stimulation caused by laryngoscopy intubation. Role of clonidine premedication administration aims to reduce cardiovascular changes of decreased blood pressure and decreased heart rate.

Objective: This study aimed to study the effect of oral clonidine tablets for blood pressure, heart rate, $Q-T c$ interval and score rate pressure product (RPP) during laryngoscopy intubation

Methods: Forty-eight subjects aged 14-40 years with ASA physical status I and II, with no sign of trouble intubation were randomly divided into groups of clonidine (KI) and the control group (K II). KI group get oral clonidine premedication $0.15 \mathrm{mg} 2$ hours before surgery, while $K 2$ placebo. Both groups received the same treatment as laryngoscopy intubation. Blood pressure, heart rate, Q-Tc interval and RPP score is calculated at 2 minutes post-induction, 2 min and 5 min after intubation laryngoscopy. Results: heart rate, RPP Score and QTc intervals did not differ significantly between the two groups. However blood pressure in the clonidine group was significantly lower in the clonidine group

Conclusions: Premedication with oral clonidine $0.15 \mathrm{mg}$ dose did not affect the Q-Tc interval, RPP scores, and heart rate were significantly laryngoscopy intubation in adult patients.
\end{abstract}

Keywords: laryngoscopy intubation, clonidine, Rate Pressure Product, QTC interval

\begin{abstract}
ABSTRAK
Latar belakang: Laringoskopi intubasi endotrakea merupakan tindakan yang banyak dilakukan pada anestesi umum tindakan laringoskopi dan intubasi selain dapat menimbulkan trauma, juga dapat menimbulkan gejolak kardiovaskuler berupa peningkatan tekanan darah, peningkatan laju jantung, peningkatan score rate pressure product (RPP) yaitu peningkatan kebutuhan oksigen jantung dan pemanjangan interval $Q-T c$ oleh stimulasi simpatik akibat laringoskopi intubasi.
\end{abstract}


Peran pemberian premedikasi klonidin bertujuan untuk mengurangi gejolak kardiovaskuler berupa penurunan tekanan darah dan penurunan laju jantung.

Tujuan: Penelitian ini bertujuan untuk mempelajari pengaruh pemberian klonidin tablet oral terhadap tekanan darah, laju jantung, interval Q-Tc dan skor rate pressure product (RPP) saat laringoskopi intubasi

Metode: Empat puluh delapan subjek berusia 14-40 tahun dengan status fisik ASA I dan II, tanpa tanda kesulitan intubasi dibagi secara acak menjadi kelompok klonidin (K I) dan kelompok kontrol (K II). Kelompok KI mendapatkan premedikasi klonidin oral 0,15 mg 2 jam sebelum operasi sedangkan K2 mendapatkan plasebo. Kedua kelompok mendapatkan perlakuan yang sama saat laringoskopi intubasi. Tekanan darah, laju jantung, interval Q-Tc dan skor RPP dihitung pada 2 menit pasca induksi, 2 menit dan 5 menit pasca laringoskopi intubasi.

Hasil: Laju jantung, Skor RPP dan interval QTc tidak berbeda bermakna antara kedua kelompok. Akan tetapi tekanan darah pada kelompok klonidin secara bermakna lebih rendah pada kelompok klonidin

Simpulan : Premedikasi klonidin oral pada dosis 0,15 mg tidak mempengaruhi interval Q-Tc, skor RPP, dan laju jantung secara bermakna pada laringoskopi intubasi pasien dewasa.

Kata kunci: laringoskopi intubasi, klonidin, Rate Pressure Product, interval QTC

\section{PENDAHULUAN}

Laringoskopi intubasi endotrakhea merupakan tindakan yang banyak dilakukan pada anestesi umum. Tindakan laringoskopi dan intubasi ini selain dapat menimbulkan trauma, juga dapat menimbulkan stimulasi simpatis, dengan akibat terjadi gejolak kardiovaskuler berupa peningkatan tekanan darah dan peningkatan laju jantung. Hal ini akan meningkatkan kebutuhan metabolik jantung dengan akibat antara lain iskemik otot jantung dan sangat membahayakan bagi penderita hipertensi, tekanan intrakranial tinggi dan penyakit jantung iskemik yang sudah dideritanya. Berbagai upaya telah dilakukan untuk mencegah ataupun mengurangi respons hemodinamik akibat tindakan laringoskopi intubasi, dilakukan dengan meningkatkan kedalaman anestesi, memberikan anestesi topikal ${ }^{1,2}$, lidokain ${ }^{2-4}$,fentanil ${ }^{3}$, beta bloker ${ }^{4}$, dan antagonis kalsium. ${ }^{5}$

Meskipun usaha-usaha tersebut dapat mengurangi respon hemodinamik tetapi belum sepenuhnya berhasil. Salah satu upaya yang lain adalah dengan memberikan premedikasi klonidin

Klonidin adalah salah satu obat golongan $\alpha-2$ agonis adrenergic yang mempunyai efek analgesik, sedasi dan efek simpatolitik. Peran pemberian premedikasi klonidin dengan efek simpatolitiknya bertujuan untuk mengurangi meningkatnya kadar katekolamin plasma, sehingga gejolak 
kardiovaskuler dapat dikurangi, dengan cara penurunan tekanan darah dan frekuensi denyut jantung ${ }^{6}$, dengan demikian dapat mengurangi peningkatan kebutuhan oksigen otot jantung.

\section{METODE}

Penelitian ini merupakan penelitian eksperimental analitik komparatif dengan desain acak. Subyek penelitian diambil secara consecutive sampling dari pasien yang menjalani tindakan bedah atau operasi elektif di Instalasi Bedah Sentral Rumah Sakit Umum Pusat Dokter Kariadi Semarang, dengan anestesi umum yang dilakukan tindakan laringoskopi dan intubasi endotrakhea dan kriteria inklusi berusia antara 14 40 tahun, status fisik ASA I atau II, pasien tanpa kesulitan intubasi (mallampati I atau II), pria dan wanita, untuk wanita tidak dalam keadaan hamil, tekanan darah dalam batas normal, tidak ada kelainan jantung, hati, ginjal dan cerebrovascular disease. Kriteria eksklusinya adalah intubasi dilakukan lebih dari satu kali, laringoskopi dan intubasi endotrakea lebih dari 30 detik, terjadi vagal reflek, perdarahan yang mengganggu airway, atau kejadian lain yang memerlukan intervensi, pada saat tindakan laringoskopi pasien masih bernafas spontan, pada saat intubasi pasien masih menunjukan adanya gerakan.

Penderita dibagi menjadi dua kelompok: Kelompok I mendapat $0,15 \mathrm{mg}$ klonidin oral 2 jam sebelum operasi dengan sedikit air putih, Kelompok II mendapat vitamin b kompleks

Seleksi penderita dilakukan pada saat kunjungan pra bedah, penderita yang memenuhi kriteria setelah mendapat penjelasan setuju mengikuti semua prosedur penelitian dan menandatangani informed consent dimasukkan sebagai sampel penelitian. Kemudian penderita diopuasakan 6 jam dan dibagi menjadi 2 kelompok secara konsekutif sampling. 2 jam sebelum operasi dengan sedikit air putih kelompok I mendapat $0,15 \mathrm{mg}$ klonidin oral sebagai kelompok perlakuan dan kelompok II mendapat vitamin B kompleks sebagai kelompok kontrol

Semua pasien direbahkan dimeja operasi lalu dipasang tensimeter dan 12 lead ECG serta monitor saturasi oksigen. Deberikan premedikasi midazolam $3 \mathrm{mg}$ lalu diinduksi dengan propofol $2 \mathrm{mg} / \mathrm{kg}$ bb. Setelah itu pasien dibaging cup dengan oksigen 3 liter dan $\mathrm{N}_{2} \mathrm{O} 3$ liter dan gas anestesi dibuka 1 MAC. Setelah airway dikuasai dengan baging pelumpuh otot atracurium bromide 0,5 $\mathrm{mg} / \mathrm{kg}$ bb. Dua menit kemudian dilakukan rekaman dan pencetakan EKG, pengukuran dan pencatatan tekanan darah dan denyut jantung sebagai data dasar.

Setelah 3 menit gas anestesi dan $\mathrm{N}_{2} \mathrm{O}$ dimatikan dan dilakukan oksigenisasi 6 liter per menit, dilanjutkan dengan laringoskopi intubasi, kemudian dievaluasi dengan stetoskop memastikan aliran udara pada kedua paru sama, selanjutnya gas anestesi dihidupkan 1 
MAC dan $\mathrm{N}_{2} \mathrm{O} 3$ liter/menit dan $\mathrm{O}_{2} 3$ liter/menit. Menit ke 2 setelah intubasi dilakukan perekaman dan pencetakan EKG, pemeriksaan dan pencatatan tekanan darah dan denyut jantung. Pemeriksaan dan perekaman EKG, dan pemeriksaan dan pencatatan tekanan darah dan denyut jantung diulangi lagi pada menit ke-5 setelah intubasi

Saturasi oksigen dan monitor EKG dipakai sebagaimonitoring selama operasi. Kemudian dihitung skore rate pressure product (RPP) Hasil kemudian dicatat, dilakukan coding, cleaning dan tabulasi. Perbandingan antara kelompok perlakuan Klonidin $\mathrm{HCl}$ dan kelompok kontrol dilakukan dengan program SPSS for Windows. Sebaran hasil akan dianalisis normalitasnya dengan uji Saphiro wilk. Apabila sebaran normal dilanjutkan dengan uji $\mathrm{t}$ independen, sedangkan apabila tidak normal akan diuji dengan uji Mann-whitney U.

\section{HASIL}

Pada penelitian ini didapat 48 sampel yang terdiri dari 24 sampel kelompok perlakuan dan 24 orang kelompok kontrol. Adapun karakteristik demografi dari sampel melanjutkan jenis kelamin, status fisik ASA, umur, berat bedan, tinggi badan, BMI dan data dasar hasil pemeriksaan pada menit ke 2 sesudah induksi, yang meliputi tekanan darah sistole, tekanan darah diastole, denyut jantung, rate pressure product dan QTC.

Semua data-data tersebut antara kelompok perlakuan dan kelompok kontrol secara statistik berbeda tidak bermakna, sehingga kedua kelompok tersebut dapat diperbandingkan dalam penelitian. Hasil selengkapnya dapat dilihat pada tabel 1 .

Pada kelompok perlakuan, laju jantung pada menit ke-2 sesudah intubasi lebih tinggi dan bermakna dibanding data dasar, sedang pada menit ke-5 sesudah intubasi lebih rendah dibandingkan data dasar. Perbedaan ini tidak bermakna. Pada kebanyakan kontrol, pada menit ke2 sesudah intubasi lebih tinggi dan bermakna dibanding data dasar, sedang pada menit ke-5 sesudah intubasi lebih tinggi dibanding data dasar, perbedaan ini secara statistik tidak bermakna. Kalau kedua kelompok dibandingkan baik pada menit ke-2 maupun ke-5 kelompok kontrol lebih tinggi secara bermakna dibandingkan kelompok perlakuan.

Pada kelompok perlakuan pada menit ke2 sesudah intubasi lebih rendah dibanding data dasar, perbedaan ini tidak bermakna. Pada menit ke-5 sesudah intubasi juga lebih rendah dibanding data dasar, perbedaan ini tidak bermakna. Pada kelompok kontrol pada menit ke-2 sesudah intubasi lebih tinggi dibanding data dasar, perbedaan ini tidak bermakna. Bila kedua kelompok ini dibandingkan baik pada menit ke-2 maupun ke-5 kelompok kontrol lebih tinggi dibandingkan kelompok perlakuan tetapi perbedaan tidak bermakna

Pada kelompok perlakuan pada menit ke2 sesudah induksi lebih tinggi dan bermakna dibanding data dasar, sedang 
pada menit ke-5 lebih rendah dibanding data dasar. Perbedaanya tidak bermakna. Pada kelompok kontrol pada menit ke-2 lebih tinggi dan bermakna dibanding data dasar, pada menit ke-5 juga lebih tinggi dibanding data dasar. Perbedaan ini tidak bermakna. Bila kedua kelompok dibandingkan baik pada menit ke-2 maupun menit ke-5 kelompok kontrol lebih tinggi, tetapi tidak bermakna.

Pada kelompok perlakuan, baik pada menit ke-2 maupun ke-5 sesudah intubasi lebih tinggi dibanding data dasar, tetapi tidak bermakna. Pada kelompok kontrol pada menit ke-2 sesudah intubasi lebih rendah tetapi pada menit ke-5 lebih tinggi dibanding data dasar, tetapi keduanya tidak bermakna.

Pada menit ke-2 sesudah intubasi kelompok perlakuan lebih tinggi dibanding kelompok kontrol, sedangkan pada menit ke-5 sesudah intubasi kelompok perlakuan lebih rendah dibanding kelompok kontrol. Tetapi kedua perbedaan tidak bermakna dibanding kelompok kontrol. Data-data hasil penelitian tersebut bisa dilihat pada tabel 2. Grafik dapat diikuti pada grafik 1, 2, 3, 4 dan 5 .

Dari data dasar menit ke-2 sesudah intubasi atau kelompok perlakuan dari kelompok kontrol Perubahan tekanan systole berbeda tidak bermakna. Sedangkan perubahan dari data dasar pada menit ke-5 sesudah intubasi, terjadi perbedaan yang bermakna diantar kelompok perlakuan dan kelompok kontrol.

Dari data dasar menit ke-2 sesudah intubasi terdapat perbedaan yang tidak bermakna tekanan diastole antara kelompok perlakuan dan kelompok kontrol. Sedangkan perubahan dari data dasar dari menit ke-2 ke menit ke-5 sesudah intubasi terjadi perbedaan yang bermakna antara kelompok perlakuan dan kelompok kontrol.

Perubahan laju denyut jantung

Dari data dasar menit ke-2 sesudah intubasi terdapat perbedaan antara kelompok perlakuan dan kelompok kontrol tidak bermakna. Perubahan dari data dasar pada menit ke-5 sesudah intubasi perbedaan antara kelompok perlakuan dan kelompok kontrol juga tidak bermakna.

Dari data dasar menit ke-2 sesudah intubasi antara kelompok perlakuan dan kelompok kontrol Rate Pressure Product berbeda tidak bermakna, demikian pula perubahan dari data dasar pada menit ke -5 sesudah intubasi perbedaan antara kelompok perlakuan dan kelompok kontrol juga tidak bermakna

Dari data dasar pada menit ke-2 sesudah intubasi interval QTc antar kelompok perlakuan dan kelompok kontrol tidak berbeda bermakna, demikian juga perubahan interval QTc atau data dasar meit ke-5 sesudah intubasi antara kelompok perlakuan dan kelompok kontrol juga tidak bermakna. 
Angka perubahan-perubahan tekanan sistole, tekanan diastole, frekuensi denyut jantung, rate pressure product dan interval QTc dapat dilihat pada tabel 3

Perubahan TDS dari induksi menit ke-2 hingga laringsoskopi intubasi menit ke2 bermakna dengan nilai P 0,00 dan perubahan dari laringoskopi intubasi menit ke-2 hingga menit ke-5 laringoskopi intubasi bermakna dengan nilai $\mathrm{P} 0,00$.

Perubahan TDD dari induksi menit ke-2 hingga laringsoskopi intubasi menit ke2 bermakna dengan nilai P 0,02 dan perubahan dari laringoskopi intubasi menit ke-2 hingga menit ke-5 laringoskopi intubasi bermakna dengan nilai $\mathrm{P} 0,00$.

Perubahan HR dari induksi menit ke-2 hingga laringsoskopi intubasi menit ke2 tidak bermakna dengan nilai $\mathrm{P} 0,70$ dan perubahan dari laringoskopi intubasi menit ke-2 hingga menit ke-5 laringoskopi intubasi bermakna dengan nilai $\mathrm{P} 0,00$.

Perubahan RPP dari induksi menit ke-2 hingga laringsoskopi intubasi menit ke2 bermakna dengan nilai $\mathrm{P} 0,02$ dan perubahanvdari laringoskopi intubasi menit ke-2 hingga menit ke-5 laringoskopi intubasi bermakna dengan nilai $\mathrm{P} 0,00$.

Perubahan QTc dari induksi menit ke-2 hingga laringsoskopi intubasi menit ke2 tidak bermakna dengan nilai $\mathrm{P} 0,30$ dan perubahan dari laringoskopi intubasi menit ke-2 hingga menit ke-5 laringoskopi intubasi tidak bermakna dengan nilai $\mathrm{P} 0,81$.

\section{PEMBAHASAN}

Gejolak peningkatan kardiovaskuler pada tindakan laringoskopi intubasi disebabkan oleh stimulus simpatis dengan akibat meningkatnya kadar kathekolamin dalam plasma darah dan menyebabkan kenaikan tekanan darah dan frekwensi denyut jantung ${ }^{6}$,karena itu pencegahannya adalah dengan mengurangi stimulus simpatis atau menghambat pengaruh simpatis. Salah satu cara adalah dengan memberikan klonidin. Beberapa peneliti menggunakan klonidin intravena membuktikan hal ini ${ }^{6,7,8}$. Tetapi terdapat juga penelitian penggunaan klonidin dengan hasil klonidin tidak bisa digunakan untuk mengatasi gejolak kardiovaskuler akibat intubasi endotrakeal $^{6,9}$. Meskipun demikian klonidin dapat mengurangi morbiditas dan mortalitas sesudah operasi non jantung ${ }^{10}$.

Pada penelitian ini baik kelompok perlakuan maupun kelompok kontrol mengalami kenaikan tekanan sistole dan diastole yang bermakna dibanding dengan data dasar dengan kelompok kontrol lebih tinggi dibanding kelompok perlakuan pada menit ke-2 sesudah intubasi. Sampai menit ke-5 kelompok kontrol tekanan sistole dan diastole masih lebih tinggi dibanding data dasar, sedangkan kelompok perlakuan lebih rendah daripada data 
dasar, sehingga tekanan sistole dan diastole menit ke-5 kelompok kontrol lebih tinggi dan bermakna dibanding kelompok perlakuan.

Frekuensi denyut jantung pada kelompok kontrol baik pada menit ke-2 lebih tinggi daripada data dasar dan kelompok perlakuan, tetapi perbedaan ini tidak bermakna

Rate pressure product baik kelompok perlakuan maupun kelompok kontrol pada menit ke-2 lebih tinggi dan bermakna dibanding data dasar. Pada menit ke-5 kelompok kontrol masih lebih tinggi tetapi tidak bermakna dibanding data dasar. Perbedaan antara kelompok perlakuan dan kelompok kontrol tidak bermakna baik pada menit ke-2 maupun menit ke-5.

QTC hanya sedikit mengalami perubahan

Melihat hal-hal diatas nampaknya pengaruh klonidin dalam penelitian ini tidak sepenuhnya bisa menghambat gejolak kardiovaskuler, terbukti masih terjadi kenaikan tekanan sistole dan diastole. Sebagai sebab karena klonidin dalam penelitian ini diberikan per oral. Hal ini sesuai dengan penelitian Zalunardo dkk bahwa klonidin oral kurang efektif dibanding intravena ${ }^{6}$.

Berbeda dengan penelitian Talebi dkk dimana klonidin oral dapat menimbulkan efek hemodinamik yang stabil pada tindakan laringoskopi intubasi ${ }^{11}$. Perbedaan dengan penelitian ini mungkin karena Talebi memberikan dosis $0,2 \mathrm{mg}$ oral, lebih tinggi dibanding penelitian ini dengan dosis $0,15 \mathrm{mg}$ oral.

Hal ini diperkuat dengan hasil penelitian Raval dkk, yang menyimpulkan bahwa klonidin oral dapat mencegah respon hemodinamik laringoskopi intubasi. Raval memberikan dosis $0,4 \mu \mathrm{g} / \mathrm{kgbb}^{12}$. Kalau dihitung dengan berat badan orang Indonesia, sekitar $60 \mathrm{~kg}$ maka kelompok yang diberikan adalah 0,24 mg, jadi lebih tinggi dari dosis yang diberikan pada penelitian ini. Penelitian Yokota dkk juga menyimpulkan klonidin dapat mencegah respon hemodinamik selama intubasi fiberoptik nasal, dosis yang dipakai $5 \mu \mathrm{g} / \mathrm{kgbb}^{13}$.

Ditinjau dari waktu pemberian obat, pada penelitian ini klonidin oral diberikan 2 jam sebelum tindakan, jadi sudah cukup waktu untuk proses absorpsi sampai menimbulkan efek farmakologis. Hal ini sesuai dengan penelitian sebelumnya dimana klonidin oral diberikan antara 90 menit - 120 menit sebelum tindakan ${ }^{6-9}$.

Menurut Abildskov, cathecolamine menyebabkan QT interval memanjang, hal ini terjadi pada penyuntikan cepat cathecolamin $^{14}$. Tindakan laringoskopi intubasi menyebabkan stimulasi simpatis dan berakibat meningkatnya chatecolamin plasma ${ }^{6}$. Hal ini diyakini akan menyebabkan QT interval memanjang, memanjangnya QT interval yang berat adalah terjadinya taki aritmia ventrikel diikuti dengan Torsades de pointes dan kematian ${ }^{15}$. 
Pada penelitian ini pemanjangan QT interval baik kelompok perlakuan maupun kelompok kontrol tidak bermakna, meskipun kelompok kontrol lebih panjang tetapi juga tidak bermakna. Hal ini berbeda dengan penelitian Sunaryo dan Endang Widiastuti sesudah laringoskopi intubasi endotrakea QTC memendek tidak bermakna, pada penelitian tersebut obat yang digunakan midazolam, penthotal dan vecuronium ${ }^{16}$ sedang pada penelitian ini menggunakan midazolam, propofol dan atracurium.

Pengaruh klonidin pada penelitian ini tidak jelas terlihat ditandai dengan masih memanjangnya QTC meskipun tidak bermakna dan ini seperti disampaikan sebelumnya bahwa sebagai penyebab adalah karena kurangnya dosis yang diberikan.

\section{SIMPULAN}

Premedikasi 5mg klonidin oral tidak berpengaruh pada perubahan Rate Pressure Product dan interval QTc

\section{DAFTAR PUSTAKA}

1. Mostafa SM, Murthy, BVS, Barrett P. J, McHugh P. Comparison of the effects of topical lignocaine spray applied before or after induction of anaesthesia on the pressor response to direct laryngoscopy and intubation. Issue European Journal of Anaesthesiology. Eur J of Anaesth January 1999;16 (1): 7-10

2. Hamill JF, Bedford RF, Weaver DC, Colohan AR. Lidocaine before endotracheal intubation: intravenous or laryngotracheal? Anesthesiology. 1981 Nov;55(5):578-581
3. Setijanto E, Susuasta IM, Budiono U. Respon Kardiovaskuler Pada Laringoskopi Intubasi Perbandingan Antara Pemberian Lidokain Dan Fentanil. Anesthesia and Crit Care 2002;23:10-18

4. Rathore A, Gupta HK, Tanwar GL. Attenuation of the pressure response to laryngoscopy and endotracheal intubation with different doses of esmolol. Indian J. Anaesth 2002;46:449-52.

5. Marwoto, Purwoko, Achmadi A. Perbandingan Efek Verapamil dan Lldokain Intravena terhadap Respon Kardiovaskuler pada Tindakan Laringoskopi Intubasi. Anesthesia and Crit Care 2002;23:10-18

6. Zalunardo MP, Serafino D, Szelloe $P$, Weisser F, Zollinger A, Seifert B, Pasch T. Preoperative clonidine blunts hyperadrenergic and hyperdynamic responses to prolonged tourniquet pressure during general anesthesia. Anesth Analg. 2002 Mar;94(3):615-8

7. Yokota S, Komatsu T, Yano K, Taki K, Shimada Y. Effect of oral clonidine premedication on hemodynamic response during sedated nasal fiberoptic intubation. Nagoya J Med Sci. 1998 May;61(1-2):4752

8. Raval et al. Oral clonidine premedication for attenuation of haemodynamic response to laryngoscopy and intubation. Indian J. Anaesth. 2002; 46: 124-129

9. Talebi $\mathrm{H}$, Nourozi A, Fateh $\mathrm{S}$, Mohammadzadeh A, Eghtesadi-Araghi P, Jabbari S, Kalantarian M. Effects of oral clonidine premedication on haemodynamic response to laryngoscopy and tracheal intubation: a clinical trial. Pak J Biol Sci. 2010 Dec 1;13(23):1146-50.

10. Harshvardhana HS. Attenuation of haemodynamic response to Laryngoscopy and tracheal intubation in adult Patients with a single bolus dose of $3 \mu \mathrm{g} / \mathrm{kg}$ body Weight of intravenous clonidine - a prospective Randomized double blind clinical study [dissertation]. Bangalore: Rajiv Gandhi University of Health Sciences; 2011.

11. Keersebilck E, De Deyne C, Struys M, 
Vissers K, Heylen R. Influence of clonidine on haemodynamic responses to endotracheal intubation after sevoflurane inhalation induction in adult patients. European Journal of Anaesthesiology 2000;17: 8

12. Tewari A, Katyal S, Singh A .Prophylaxis with oral clonidine prevents perioperative shivering in patients undergoing transurethral resection of prostate. Indian Journal of Urology 2006: 122-35

13. Wallace A., Ratcliffe M.B., Galindez D., and Kong J.S. L-Arginine Infusion Dilates Coronary Vasculature in Patients Undergoing Coronary Bypass Surgery. Anesthesiology 90(6): 1577-1586, 1999.
14. Abildskov J, My G. Atrial fibrillation as self-sustaining arrhythmia independent of focal discharge. Am. Heart. J. 1959; 5 (58): 59-70.

15. Schwartz PJ, Stramba-Badiale M, Segantini A, Austoni P, Bosi G, Giorgetti R, Grancini F, Marni ED, Perticone F, Rosti D, Salice $\mathrm{P}$. Prolongation of the QT interval and the sudden infant death syndrome. N Engl J Med. 1998 Jun 11;338(24):1709-14.

16. Soenarjo, Widiyastuti E. Perubahan interval QTc akibat induksi anestesi dan intubasi, Media Medika Indonesia. 2001; 36 (2): 67-71. 